\title{
The relationship between neutrophil/lymphocyte, monocyte/ /lymphocyte, platelet/lymphocyte ratios and clinical outcomes after ninety days in patients who were diagnosed as having acute ischemic stroke in the emergency room and underwent a mechanical thrombectomy
}

\author{
Ozgen $\mathrm{E}^{1}$, Guzel $\mathrm{M}^{2}$, Akpinar $\mathrm{CK}^{3}$, Yucel $\mathrm{M}^{4}$, Demir $\mathrm{MT}^{2}$, Baydin $\mathrm{A}^{5}$ \\ Department of Emergency Medicine, Merzifon Karamustafapasa State Hospital, Amasya, Turkey. \\ emreozgen46523@gmail.com
}

\begin{abstract}
AIM: To determine whether there was a relationship between the neutrophil/lymphocyte (NLR), monocyte/ /lymphocyte (MLR), and the platelet/lymphocyte ratios (PLR) measured in blood samples taken at admission and clinical outcomes (CO) on the 90th day in patients, who were diagnosed as acute ischemic stroke (AIS) in the emergency department (ED) and underwent a mechanical thrombectomy (MT).

METHOD: Patients aged $\geq 18$ years, who were diagnosed as AIS in the ED and underwent MT were included in the study. Patients, who received diagnostic codes of "Cerebrovascular Diseases" (CVD) according to the ICD-10 diagnostic codes were identified. One hundred fifty patients were enrolled in the study. Modified Rankin Scale (mRS) score was used to determine neurologic status on the 90th day. The patients were divided into the two groups: good and poor $\mathrm{CO}$ ( $\mathrm{mRS} 0-2$ and $\mathrm{mRS} 3-6$, respectively). The groups were compared in terms of age, sex, and NIHSS, ASPECT, and mRS scores.

RESULTS: The rates of successful recanalization and good CO were $81.3 \%$ and $38.7 \%$, respectively. The mortality rate was $22 \%$. The recanalization rates in the good and poor CO groups were $100 \%$ and $69.6 \%$, respectively. Recanalization was achieved in $73.6 \%$ of those with hyperlipidaemia and $88.5 \%$ of those without hyperlipidaemia, which was statistically significant $(p=0.034)$. We observed a statistically significant relationship between the clinical outcome and NLR, MLR, PLR $(p<0.05)$. As the result of multivariate analysis, we found only NLR as an independent risk factor for poor CO $(p=0.043)$. There was also a statistically significant difference between mortality and NLR, PLR $(p=0.001)$.

CONCLUSION: We found that NLR, MLR, PLR values were associated with CO after 90 days; high rates were associated with poor $\mathrm{CO}$ and low rates were associated with good $\mathrm{CO}$ (Tab. 7, Ref. 38). Text in PDF www.elis.sk

KEY WORDS: acute ischemic stroke; neutrophil/lymphocyte ratio, monocyte/lymphocyte ratio; platelet/ /lymphocyte ratio; thrombectomy.
\end{abstract}

\section{Aim and introduction}

Stroke is responsible for a significant portion of mortality and has been the third most common cause of mortality worldwide for the last 50 years (1). Acute ischemic stroke (AIS) occurs due to thrombotic mechanisms, embolic mechanisms or hypoperfusion and accounts

${ }^{1}$ Department of Emergency Medicine, Merzifon Karamustafapasa State Hospital, Amasya, Turkey, ${ }^{2}$ Department of Emergency Medicine, Samsun Training and Research Hospital, Samsun, Turkey, ${ }^{3}$ Department of Neurology, Samsun Training and Research Hospital, Samsun, Turkey, ${ }^{4}$ Department of Emergency Medicine, Faculty of Medicine, Sakarya University, Sakarya, Turkey, and ${ }^{5}$ Department of Emergency Medicine, Faculty of Medicine, Ondokuz Mayis University, Samsun, Turkey

Address for correspondence: E. Ozgen, MD, Department of Emergency Medicine, Merzifon Karamustafapasa State Hospital, Amasya, Turkey. Phone: +90.5308850077 for $87 \%$ of all the strokes (2). Standard treatment of AIS consists of the use of tissue plasminogen activator (tPA) and mechanical thrombectomy for the recanalization of occlusion in brain vessels. Many clinical studies showed the benefits of endovascular recanalization in occlusions of the anterior circulation (3-6). Studies published after the second half of the 1990s showed that intravenous (IV) tPA in AIS has been beneficial when given in the hours immediately after the onset of the symptoms (7). The European Stroke Organization (ESO) refers to mechanical thrombectomy as the first-line treatment in patients with AIS in whom there is large vessel occlusion and IV thrombolytic therapy is contraindicated. The guidelines suggest a mechanical thrombectomy in combination with IV thrombolytic therapy in the treatment of patients with proximal occlusion within the first 6 hours. Accordingly, IV thrombolytic therapy should be started within 4.5 hours in eligible cases and mechanical thrombectomy should be performed within 6 hours of symptom onset (8). 
In some previous studies, the ratios of neutrophils/lymphocytes (NLR), monocytes/lymphocytes (MLR), and platelets/lymphocytes (PLR) were shown to be indicative of systemic inflammation, to play an important role in venous thromboembolism, and to be effective in determining the tendency to thrombosis (9-11). NLR and PLR were reported to be better indicators of inflammation than leukocyte counts in the whole blood counts (12), and NLR was shown to be an indicator of prognosis in cancer, cardiac diseases, pulmonary embolism, and sepsis (13-21). As far as we know, there was no study that investigated the relationship between NLR, MLR, PLR and clinical outcomes in patients with AIS undergoing a mechanical thrombectomy.

Our aim in this study was to determine whether there was a relationship between NLR, MLR, PLR measured in blood samples taken at admission and clinical outcomes on the 90th day in patients, who were diagnosed with AIS in the emergency department and underwent a mechanical thrombectomy.

\section{Materials and methods}

This study was approved by Samsun Training and Research Hospital Ethics Committee on May 29, 2018 (Session No.: 2018/14, Decision No.: TUEK 112-2018 GOKAEK/1-2). Mechanical thrombectomy for AIS began to be performed on January 1, 2017; therefore, patients who were diagnosed with AIS in the emergency department and underwent a mechanical thrombectomy between January 1, 2017, and May 29, 2018, were enrolled in the study. For this purpose, patients, who received "Cerebrovascular Diseases" (SVH) diagnostic codes according to the International Statistical Classification of Diseases and Related Health Problems (ICD-10) diagnostic codes were identified through the hospital information system and their files were obtained. Those, who underwent a mechanical thrombectomy were included in the study. A data collection form was created to collect data in a standard manner. In the data collection form; age, sex, known diseases, laboratory findings (e.g. glucose, urea, creatinine, leukocytes, neutrophils, lymphocytes, monocytes, and platelets) were included. The National Institutes of Health Stroke Scale (NIHSS) score was used to determine the neurologic status at admission, and the Alberta Stroke Program Early Computed Tomography (ASPECT) and Modified Rankin Scale (mRS) scores were used to determine the neurologic status on the 90th day. The patients were divided into the two groups: patients with good clinical outcomes (mRS 0-2) and patients with poor clinical outcomes (mRS 3-6). The groups were compared in terms of age, sex, and NIHSS, ASPECT, and mRS scores. The relationship between NLR, MLR, PLR ratios and clinical outcome was investigated.

\section{Inclusion and exclusion criteria}

The study included patients aged over 18 years, who had AIS and underwent a mechanical thrombectomy.

Exclusion criteria: patients with hematologic malignancies, patients younger than 18 years, patients treated for infection for the last two weeks or patients having signs of active infection, patients with known collagen tissue diseases, patients with a history of gastrointestinal bleeding or major trauma within the last one week, and patients using immunosuppressive drugs.

\section{Statistical analysis}

The data were analysed using the IBM SPSS V23 software package. Conformance to normal distribution was examined using the Shapiro-Wilk test. The Mann-Whitney U test was used to compare data without normal distribution with recanalization, clinical outcomes, and mortality. The Chi-square test was used to compare categorical data. Independent risk factors of mortality and good clinical outcomes were analysed using univariate and multivariate logistic regression analyses. The results of the analyses are presented as the median (min-max) for quantitative data, and categorical data are presented as frequency (percentage). The level of statistical significance was accepted as $\mathrm{p}<0.05$.

\section{Results}

Of the patients in the study, $44.7 \%$ were female and $55.3 \%$ were male. The rate of successful recanalization was $81.3 \%$, and the rate of good clinical outcome was $38.7 \%$. The distributions of patients according to categorical data are given in Table 1 .

There was no statistically significant relationship between recanalization and sex, hypertension (HT), diabetes mellitus (DM), atrial fibrillation (AF), and coronary artery disease (CAD) ( $p$ > $0.05)$. There was a statistically significant relationship between

Tab. 1. The distributions of patients according to categorical data.

\begin{tabular}{|c|c|c|}
\hline & Number (n) & Percent $(\%)$ \\
\hline \multicolumn{3}{|l|}{ Sex } \\
\hline Female & 67 & 44.7 \\
\hline Male & 83 & 55.3 \\
\hline \multicolumn{3}{|l|}{ Recanalization success } \\
\hline Recanalization was achieved & 122 & 81.3 \\
\hline Recanalization was not achieved & 28 & 18.7 \\
\hline \multicolumn{3}{|l|}{ Clinical outcome } \\
\hline Good clinical outcome & 58 & 38.7 \\
\hline Poor clinical outcome & 92 & 61.3 \\
\hline \multicolumn{3}{|l|}{ HT } \\
\hline- & 12 & 8.0 \\
\hline+ & 138 & 92.0 \\
\hline \multicolumn{3}{|l|}{$\overline{\mathrm{DM}}$} \\
\hline- & 108 & 72.0 \\
\hline+ & 42 & 28.0 \\
\hline \multicolumn{3}{|l|}{$\overline{\mathrm{AF}}$} \\
\hline- & 112 & 74.7 \\
\hline+ & 38 & 25.3 \\
\hline \multicolumn{3}{|l|}{$\overline{\mathrm{HL}}$} \\
\hline- & 72 & 48.0 \\
\hline+ & 78 & 52.0 \\
\hline \multicolumn{3}{|l|}{ CAD } \\
\hline- & 96 & 64.0 \\
\hline+ & 54 & 36.0 \\
\hline \multicolumn{3}{|l|}{ Mortality } \\
\hline Live & 117 & 78.0 \\
\hline Dead & 33 & 22.0 \\
\hline
\end{tabular}


Tab. 2. Comparison of categorical data according to recanalization success.

\begin{tabular}{|c|c|c|c|c|}
\hline & \multicolumn{2}{|c|}{ Recanalization } & \multirow{2}{*}{$\begin{array}{c}\text { Test } \\
\text { statistics }\end{array}$} & \multirow[b]{2}{*}{$\mathrm{p}$} \\
\hline & $\begin{array}{c}\text { achieved } \\
\mathrm{n}(\%)\end{array}$ & $\begin{array}{c}\text { Not achieved } \\
n(\%)\end{array}$ & & \\
\hline \multicolumn{5}{|l|}{ Sex } \\
\hline Female & $55(82.1)$ & $12(17.9)$ & $\chi^{2}=0.046$ & 0.998 \\
\hline Male & $67(80.7)$ & $16(19.3)$ & & \\
\hline \multicolumn{5}{|l|}{ Clinical outcome } \\
\hline Good clinical outcome & $58(100)$ & $0(0)$ & $\chi^{2}=19.745$ & $<0.001$ \\
\hline Poor clinical outcome & $64(69.6)$ & $28(30.4)$ & & \\
\hline \multicolumn{5}{|l|}{ HT } \\
\hline- & $8(66.7)$ & $4(33.3)$ & $\chi^{2}=1.848$ & 0.174 \\
\hline+ & $114(82.6)$ & $24(17.4)$ & & \\
\hline \multicolumn{5}{|l|}{$\overline{\mathrm{DM}}$} \\
\hline- & $91(84.3)$ & $17(15.7)$ & $\chi^{2}=1.541$ & 0.214 \\
\hline+ & $31(73.8)$ & $11(26.2)$ & & \\
\hline \multicolumn{5}{|l|}{$\overline{\mathrm{AF}}$} \\
\hline- & $90(80.4)$ & $22(19.6)$ & $\chi^{2}=0.082$ & 0.775 \\
\hline+ & $32(84.2)$ & $6(15.8)$ & & \\
\hline \multicolumn{5}{|l|}{$\overline{\mathrm{HL}}$} \\
\hline- & $53(73.6)$ & $19(26.4)$ & $\chi^{2}=4.504$ & 0.034 \\
\hline+ & $69(88.5)$ & $9(11.5)$ & & \\
\hline \multicolumn{5}{|l|}{$\overline{\mathrm{CAD}}$} \\
\hline- & $79(82.3)$ & $17(17.7)$ & $\chi^{2}=0.034$ & 0.855 \\
\hline+ & $43(79.6)$ & $11(20.4)$ & & \\
\hline \multicolumn{5}{|l|}{ Mortality } \\
\hline Live & $99(84.6)$ & $18(15.4)$ & $\chi^{2}=2.855$ & 0.091 \\
\hline Dead & $23(69.7)$ & $10(30.3)$ & & \\
\hline
\end{tabular}

$\chi^{2}$ - Chi-square test statistics, AF - Atrial Fibrillation, DM - Diabetes Mellitus, HT hypertension, $\mathrm{CAD}$ - Coronary Artery Disease, $\mathrm{HL}$ - Hyperlipidemia

Tab. 4. Comparison of quantitative data according to clinical outcome.

\begin{tabular}{|c|c|c|c|c|}
\hline & \multicolumn{2}{|c|}{ Clinical outcome } & \multirow{2}{*}{ Test statistics } & \multirow{2}{*}{$\mathrm{p}$} \\
\hline & Good & Poor & & \\
\hline Age (year) & $64(36-80)$ & $68.5(32-87)$ & $\mathrm{U}=2253.5$ & 0.109 \\
\hline Time (minute) & $245(120-385)$ & $250(125-420)$ & $U=2235$ & 0.094 \\
\hline NIHSS & $13.5(6-20)$ & $16(4-24)$ & $\mathrm{U}=2045.5$ & 0.016 \\
\hline ASPECT & $9(6-10)$ & $8(5-10)$ & $\mathrm{U}=2159.5$ & 0.043 \\
\hline Systolic Blood Pressure (mmHg) & $150(80-190)$ & $160(110-220)$ & $\mathrm{U}=1763$ & $<0.001$ \\
\hline Diastolic Blood Pressure (mmHg) & $87.5(50-110)$ & $90(60-120)$ & $\mathrm{U}=2016.5$ & 0.010 \\
\hline Pulse Rate / Min & $74(60-100)$ & $77(64-117)$ & $\mathrm{U}=1890.5$ & 0.003 \\
\hline Fever $\left({ }^{\circ} \mathrm{C}\right)$ & $36.4(36-37)$ & $36.4(36-37.8)$ & $\mathrm{U}=2554$ & 0.655 \\
\hline BMI $\left(\mathrm{kg} / \mathrm{m}^{2}\right)$ & $27.7(22-35.2)$ & $27.5(22-35.4)$ & $\mathrm{U}=2363.5$ & 0.239 \\
\hline Sodium $(\mathrm{mEq} / \mathrm{L})$ & $138(128-158)$ & $138(117-148)$ & $\mathrm{U}=2136.5$ & 0.039 \\
\hline Glucose (mg/dL) & $121.5(82-447)$ & $157.5(85-691)$ & $\mathrm{U}=1932.5$ & 0.005 \\
\hline Leukocyte & $9.5(4.3-27.4)$ & $10.2(6.4-20.7)$ & $\mathrm{U}=2178$ & 0.059 \\
\hline $\mathrm{Hb}(\mathrm{gr} / \mathrm{dL})$ & $12.7(7.8-16.6)$ & $12.8(8.4-17.4)$ & $\mathrm{U}=2556.5$ & 0.667 \\
\hline Htc & $37.8(27.1-47.7)$ & $37.2(25.8-50.4)$ & $\mathrm{U}=2635$ & 0.899 \\
\hline RDW & $14.4(12.1-21)$ & $14.1(12.5-25.3)$ & $\mathrm{U}=2530.5$ & 0.595 \\
\hline Plt & $234(47-428)$ & $220.5(104-379)$ & $\mathrm{U}=2558.5$ & 0.673 \\
\hline Neutrophil & $6.8(1.8-23.7)$ & $8.5(3.2-17.3)$ & $\mathrm{U}=1902.5$ & 0.003 \\
\hline Lymphocyte & $1.9(1-4.6)$ & $1.3(0.5-4.8)$ & $\mathrm{U}=1578.5$ & $<0.001$ \\
\hline Monocytes & $0.5(0.2-8.2)$ & $0.5(0.1-1.3)$ & $\mathrm{U}=2647$ & 0.935 \\
\hline Urea & $34(20-116)$ & $44(19-137)$ & $\mathrm{U}=2103.5$ & 0.029 \\
\hline Creatinine (mg/dL) & $0.8(0.5-1.7)$ & $0.9(0.5-5.4)$ & $\mathrm{U}=2165.5$ & 0.050 \\
\hline Neutrophil/Lymphocyte & $3.5(0.4-21.6)$ & $6.9(0.7-24.7)$ & $\mathrm{U}=1438.5$ & $<0.001$ \\
\hline Monocyte/Lymphocyte & $0.3(0.1-2.2)$ & $0.4(0-1.1)$ & $\mathrm{U}=1788$ & 0.001 \\
\hline Plt/Lymphocyte & $124(11.2-229.1)$ & $161(62.1-541.4)$ & $\mathrm{U}=1691$ & $<0.001$ \\
\hline
\end{tabular}

Tab. 3. Comparison of categorical data by clinical outcome.

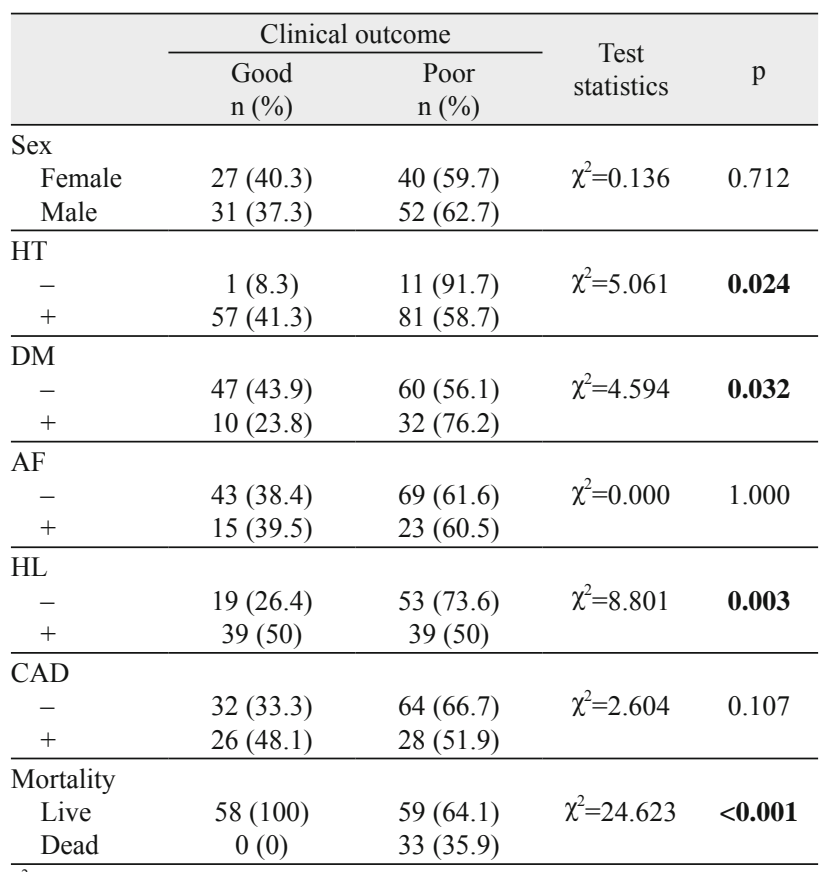

$\chi^{2}-$ Chi-square test statistics, AF - Atrial Fibrillation, DM - Diabetes Mellitus, HT hypertension, CAD - Coronary Artery Disease, HL - Hyperlipidemia

good clinical outcome and recanalization $(\mathrm{p}<0.001)$. Recanalization rate was $100 \%$ in those with good clinical outcome and $69.6 \%$ in those with poor clinical outcome. Recanalization was achieved in $73.6 \%$ of those with hyperlipidemia (HL) and $88.5 \%$ of those without HL, and this difference was statistically significant $(\mathrm{p}=$ 0.034) (Tab. 2).

Although there was no statistically significant relationship between the clinical outcome and sex, AF, and CAD ( $p>0.05)$, there was a statistically significant relationship between the clinical outcome and HT, DM, HL (p < 0.05) (Tab. 3).

We observed no statistically significant relationship between the clinical outcome and age, duration, fever, body mass index (BMI), leukocyte, haemoglobin, haematocrit, RDW, platelet count, monocyte count, and creatinine $(p>0.05)$. There was a statistically significant relationship between the clinical outcome and NIHSS, ASPECT, blood pressure, pulse, sodium, glucose, neutrophil count, lymphocyte count, NLR, MLR, PLR, and PNR ( $<$ 0.05) (Tab. 4).

There was no statistically significant relationship between mortality and sex, $\mathrm{DM}$, and AF ( $\mathrm{p}>0.05)$, but there was a statistically significant relationship between mortality and HT, HL, and CAD $(\mathrm{p}<0.05)$ (Tab. 5). 
Tab. 5. Comparison of categorical data according to mortality.

\begin{tabular}{|c|c|c|c|c|}
\hline & \multicolumn{2}{|c|}{ Mortality } & \multirow{2}{*}{$\begin{array}{c}\text { Test } \\
\text { statistics }\end{array}$} & \multirow[b]{2}{*}{$\mathrm{p}$} \\
\hline & $\begin{array}{l}\text { Live } \\
\mathrm{n}(\%)\end{array}$ & $\begin{array}{l}\text { Dead } \\
\mathrm{n}(\%)\end{array}$ & & \\
\hline \multicolumn{5}{|l|}{ Sex } \\
\hline Female & $49(73.1)$ & $18(26.9)$ & $\chi^{2}=1.197$ & 0.274 \\
\hline Male & $68(81.9)$ & $15(18.1)$ & & \\
\hline \multicolumn{5}{|l|}{ HT } \\
\hline- & $5(41.7)$ & $7(58.3)$ & $\chi^{2}=7.865$ & 0.005 \\
\hline+ & $112(81.2)$ & $26(18.8)$ & & \\
\hline \multicolumn{5}{|l|}{$\overline{\mathrm{DM}}$} \\
\hline- & $88(81.5)$ & $20(18.5)$ & $\chi^{2}=2.048$ & 0.152 \\
\hline+ & $29(69)$ & $13(31)$ & & \\
\hline \multicolumn{5}{|l|}{$\mathrm{AF}$} \\
\hline- & $86(76.8)$ & $26(23.2)$ & $\chi^{2}=0.152$ & 0.697 \\
\hline+ & $31(81.6)$ & $7(18.4)$ & & \\
\hline \multicolumn{5}{|l|}{$\overline{\mathrm{HL}}$} \\
\hline- & $48(66.7)$ & $24(33.3)$ & $\chi^{2}=9.133$ & 0.003 \\
\hline+ & $69(88.5)$ & $9(11.5)$ & & \\
\hline \multicolumn{5}{|l|}{ CAD } \\
\hline- & $82(85.4)$ & $14(14.6)$ & $\chi^{2}=7.390$ & 0.007 \\
\hline+ & $35(64.8)$ & $19(35.2)$ & & \\
\hline
\end{tabular}

$\chi^{2}$-Chi-square test statistics, AF - Atrial Fibrillation, DM - Diabetes Mellitus, HT hypertension, $\mathrm{CAD}$ - Coronary Artery Disease, $\mathrm{HL}$ - Hyperlipidemia

There was no statistically significant relationship between mortality and age, ASPECT score, blood pressure, fever, BMI, glucose, leukocyte count, haemoglobin, haematocrit, RDW, platelet, neutrophil, monocyte and lymphocyte counts, urea, creatinine

Tab. 6. Comparison of quantitative data according to mortality.

\begin{tabular}{|c|c|c|c|c|}
\hline & \multicolumn{2}{|c|}{ Mortality } & \multirow{2}{*}{ Test statistics } & \multirow{2}{*}{$\mathrm{p}$} \\
\hline & Live & Dead & & \\
\hline Age (year) & $66(33-81)$ & $72(32-87)$ & $\mathrm{U}=1579$ & 0.110 \\
\hline Time (minute) & $245(120-420)$ & $265(160-420)$ & $\mathrm{U}=1408$ & 0.018 \\
\hline NIHSS & $15(6-24)$ & $14(4-24)$ & $\mathrm{U}=1477.5$ & 0.039 \\
\hline ASPECT & $8(6-10)$ & $9(5-10)$ & $\mathrm{U}=1704.5$ & 0.291 \\
\hline Systolic Blood Pressure (mmHg) & $150(80-220)$ & $160(110-220)$ & $\mathrm{U}=1707$ & 0.307 \\
\hline Diastolic Blood Pressure (mmHg) & $90(50-120)$ & $90(60-110)$ & $\mathrm{U}=1878.5$ & 0.809 \\
\hline Pulse Rate / Min & $76(60-110)$ & $82(64-117)$ & $\mathrm{U}=1277.5$ & 0.003 \\
\hline Fever $\left({ }^{\circ} \mathrm{C}\right)$ & $36.4(36-38)$ & $36.4(36-38)$ & $\mathrm{U}=1819.5$ & 0.608 \\
\hline BMI $\left(\mathrm{kg} / \mathrm{m}^{2}\right)$ & $27.7(22-35)$ & $26.8(23-33)$ & $\mathrm{U}=1697.5$ & 0.290 \\
\hline Sodium $(\mathrm{mEq} / \mathrm{L})$ & $138(117-158)$ & $137(129-142)$ & $\mathrm{U}=1457$ & 0.031 \\
\hline Glucose (mg/dL) & $136(82-691)$ & $142(95-321)$ & $\mathrm{U}=1584.5$ & 0.116 \\
\hline Leukocyte & $9.8(4-27)$ & $10.6(6-15)$ & $\mathrm{U}=1654.5$ & 0.210 \\
\hline $\mathrm{Hb}(\mathrm{gr} / \mathrm{dL})$ & $12.7(8-17)$ & $12.8(8-16)$ & $\mathrm{U}=1898$ & 0.883 \\
\hline Htc & $37.4(27-50)$ & $37.1(26-48)$ & $\mathrm{U}=1883.5$ & 0.831 \\
\hline RDW & $14.3(12-25)$ & $14.5(13-21)$ & $\mathrm{U}=1821.5$ & 0.621 \\
\hline Plt & $223(47-428)$ & $230(146-377)$ & $\mathrm{U}=1704$ & 0.304 \\
\hline Neutrophil & $7(2-24)$ & $8.8(4-13)$ & $\mathrm{U}=1511.5$ & 0.057 \\
\hline Lymphocyte & $1.6(1-5)$ & $1.3(1-4)$ & $\mathrm{U}=1555.5$ & 0.089 \\
\hline Monocytes & $0.5(0-8)$ & $0.5(0-1)$ & $\mathrm{U}=1929$ & 0.995 \\
\hline Urea & $39(19-137)$ & $46(19-71)$ & $\mathrm{U}=1750.5$ & 0.414 \\
\hline Creatinine (mg/dL) & $0.9(1-5)$ & $0.9(1-2)$ & $\mathrm{U}=1889$ & 0.849 \\
\hline Neutrophil/Lymphocyte & $4.2(0-25)$ & $6.5(2-15)$ & $\mathrm{U}=1469.5$ & 0.036 \\
\hline Monocyte/Lymphocyte & $0.3(0-2)$ & $0.4(0-1)$ & $\mathrm{U}=1540.5$ & 0.077 \\
\hline Plt/Lymphocyte & $130(11-541)$ & $159.3(80-411)$ & $\mathrm{U}=1447$ & 0.028 \\
\hline
\end{tabular}

U-Mann-Whitney U test statistics, BMI - Body mass index, Hb - Hemoglobin, Htc - Hemotokrit, Plt - Platelet and MLR ratio ( $\mathrm{p}>0.05)$, but there was a statistically significant relationship between mortality and duration, NIHSS score, pulse, value of sodium, NLR, and PLR ratios $(\mathrm{p}<0.05)$ (Tab. 6).

According to univariate test results, we found that recanalization success, BMI, and glucose were not risk factors, whereas NLR, MLR, and PLR ratios were risk factors for poor clinical outcome. The increase in NLR increased the risk of poor clinical outcome by 1.266 times. The increase in MLR increased the risk of poor clinical outcome by 4.178 times, and the increase in PLR increased risk by 1.012 times.

As the result of multivariate analysis, we found that only NLR was an independent risk factor $(\mathrm{p}=0.043)$. The increase in NLR increased the risk of poor clinical outcome by 1.347 times (Tab. 7).

\section{Discussion}

To the best of our knowledge, no studies investigated the relationship between NLR, MLR, PLR and clinical outcomes in patients with AIS undergoing a mechanical thrombectomy. It is known that immune response is vital in pathogenesis of AIS and that ischemic and anoxic brain tissues trigger the migration of leukocytes in peripheral blood to the damaged area. Neutrophils are the first migrating blood cells to the ischemic area, secreting inflammatory mediators, causing an increased damage to the ischemic area. By different mechanisms, such as. interaction with platelet and coagulation factors and release of proteases, neutrophils promote ischemia by inducing thrombosis (22). The number of studies on diagnostic value of blood cell ratios and their predictive values in diseases, has recently shown an increase. Although these ratios are easy to measure, it has been shown in many studies that there is a strong correlation between them and cerebral ischemia (23). Lim et al investigated the predictive value of PLR and NLR in demonstrating the severity of the disease in patients with AIS and transient ischemic attack (TIA), concluding that they were valuable predictive markers (24). Altintas et al showed a relationship between an increased PLR and increased infarction volume and the incidence of poor prognosis in patients with AIS (25). We found a statistically significant difference between the groups with good and poor clinical outcomes in terms of the ASPECT, similar to other studies. We found the ASPECT score was significantly lower in patients with poor clinical outcomes.

Platelet activation and aggregation are important in the pathogenesis of AIS. In pathologic conditions, over-activation and aggregation of platelets can cause thrombosis and vascular occlusion, which can result in ischemic stroke and ischemic heart disease (26). Many studies showed that platelet 
Tab. 7. Identification of independent risk factors affecting good clinical outcome.

\begin{tabular}{|c|c|c|c|c|}
\hline & \multicolumn{2}{|l|}{ Univariate } & \multicolumn{2}{|l|}{ Multivariate } \\
\hline & OR (\%95 GA) & $\mathrm{p}$ & OR (\%95 GA) & $\mathrm{p}$ \\
\hline Recanalization success & $1464024076(0-0)$ & 0.998 & $1471309743.837(0-0)$ & 0.998 \\
\hline BMI & $0.943(0.860-1.035)$ & 0.217 & $0.962(0.858-1.08)$ & 0.515 \\
\hline Glucose & $1.006(1.000-1.012)$ & 0.045 & $1.003(0.997-1.01)$ & 0.330 \\
\hline NLR & $1.266(1.133-1.414)$ & $<0.001$ & $1.347(1.01-1.796)$ & 0.043 \\
\hline MLR & $4.178(1.137-15.351)$ & 0.031 & $1.361(0.32-5.794)$ & 0.676 \\
\hline PLR & $1.012(1.006-1.018)$ & $<0.001$ & $1.001(0.99-1.013)$ & 0.840 \\
\hline
\end{tabular}

underwent a mechanical thrombectomy, and reported that systolic blood pressure above $180 \mathrm{~mm} \mathrm{Hg}$ before thrombectomy had a detrimental effect on good clinical outcomes, and also increased mortality (38). In our study, we also found that there was a statistically significant relationship between systolic and diastolic blood pressures at the time of admission to the emergency room and clinical outcome in patients undergo-

distribution width (PDW) and the mean platelet width (MPW) are increased, whereas platelet numbers are decreased in the circulatory systems of patients with AIS $(27,28)$. In their study, Soylu et al reported that PLR correlated with carotid stenosis in patients with AIS (29). In our study, we observed that PLR differed according to the clinical outcome, but found no differences in platelet counts.

Treatment of AIS is limited to IV or intraarterial tPA and mechanical endovascular treatments. These strategies benefit eligible patients, but involve some risks. When performing recanalization treatments, the decision is made after profit/loss comparisons are made. The most commonly evaluated stroke risk factors are age, infarction volume, and the NIHSS score $(30,31)$. In our study, we found that the median values of NIHSS differed according to the clinical outcomes.

Measuring the degree of immune dysfunction immediately after stroke can offer prognostic information to determine which patients will respond most appropriately to endovascular intervention. Neutrophils play a critical role in atherosclerosis and are important in plaque rupture, reperfusion damage, and plaque remodelling (32). Massiot et al found that the ratios of NLR and PLR were significantly associated with the severity of symptomatic internal carotid artery stenosis (33). In their study, Pektezel et al investigated the NLR value and immune response to thrombolytic therapy in patients with AIS and reported that increased NLR was a marker of acute stress response associated with stroke during the first 24 hours and was associated with poor prognosis, but that the pre-treatment NLR value had no importance in predicting response to IV tPA (34). In our study, we determined that NLR, MLR, and PLR values were effective in determining the clinical outcomes.

NLR is a marker of systemic inflammation and has been reported in recent studies to be an important marker of post-AIS 60-day mortality (35). Petrone et al investigated patients' immune response to AIS and its effects on diagnosis, treatment, and prognosis, and reported that the ratio of NLR was predictive and was an important marker in AIS (36). Brooks et al investigated the relationship between NLR evaluated at the time of admission to the emergency room and the clinical outcome of patients with AIS on the 90th day after endovascular stroke treatment and reported that NLR was associated with the clinical outcome (37). In our study, MLR and PLR values along with NLR values were risk factors for poor clinical outcome on the 90th day after mechanical thrombectomy. As the result of multivariate analysis, we found that only NLR was an independent risk factor for a poor clinical outcome $(p=0.043)$.

Maier et al investigated the level of mortality and disability according to baseline blood pressure in patients with AIS, who ing a mechanical thrombectomy, but there was no significant relationship between blood pressure and mortality. We thought that this difference was due to the heterogeneous distribution of blood pressures in the patients in our study. In our study, we also found that NLR and PLR were related with mortality $(p<0.001)$, similar to other studies.

Our study had limitations specific to retrospective studies. It was difficult to access all the data because the data recording system and files were scanned retrospectively.

\section{Conclusions}

The NLR, MLR, and PLR were associated with the clinical outcome on 90th day in patients undergoing mechanical thrombectomy; high rates were associated with a poor clinical outcome and low rates were associated with a good clinical outcome. NLR and PLR are parameters that could be used to predict mortality in patients with AIS.

\section{References}

1. Krishnamurthi RV, Feigin VL, Forouzanfar MH et al. Global and regional burden of first-ever ischaemic and haemorrhagic stroke during 1990-2010: findings from the Global Burden of Disease Study 2010. Lancet Glob Health 2013; 1 (5): e259-281.

2. Benjamin EJ, Blaha MJ, Chiuve SE et al. Heart Disease and Stroke Statistics-2017 Update: A Report from the American Heart Association. Circulation 2017; 135 (10): e146-e603.

3. Kalogeris T, Baines CP, Krenz M, Korthuis RJ. Ischemia/Reperfusion. Compr Physiol 2016; 7 (1): 113-170.

4. Berkhemer OA, Fransen PS, Beumer D et al. A randomized trial of intraarterial treatment for acute ischemic stroke. N Engl J Med 2015; 372 (1): 11-20.

5. Goyal M, Menon BK, van Zwam WH et al. Endovascular thrombectomy after large-vessel ischaemic stroke: a meta-analysis of individual patient data from five randomised trials. Lancet (London, England) 2016; 387 (10029): 1723-1731.

6. Saver JL, Goyal M, Diener HC. Stent-Retriever Thrombectomy for Stroke. N Engl J Med 2015; 373 (11): 1077.

7. Feigin VL, Nguyen G, Cercy K et al. Global, Regional, and CountrySpecific Lifetime Risks of Stroke, 1990 and 2016. N Engl J Med 2018; 379 (25): 2429-2437.

8. Jovin TG, Chamorro A, Cobo $\mathrm{E}$ et al. Thrombectomy within 8 hours after symptom onset in ischemic stroke. N Engl J Med 2015; 372 (24): 2296-2306 
9. Tang Y, Xu H, Du X et al. Gene expression in blood changes rapidly in neutrophils and monocytes after ischemic stroke in humans: a microarray study. J Cereb Blood Flow Metab 2006; 26 (8): 1089-102.

10. Yamagami S, Tamura M, Hayashi M et al. Differential production of MCP-1 and cytokine-induced neutrophil chemoattractant in the ischemic brain after transient focal ischemia in rats. J Leukoc Biol 1999; 65 (6): 744-749.

11. Sonmez O, Ertas G, Bacaksiz A et al. Relation of neutrophil-to-lymphocyte ratio with the presence and complexity of coronary artery disease: an observational study. Anadolu Kardiyol Derg 2013; 13 (7): 662-667.

12. Global, regional, and national age-sex specific mortality for 264 causes of death, 1980-2016: a systematic analysis for the Global Burden of Disease Study 2016. Lancet 2017; 390 (10100): 1151-1210.

13. Walsh SR, Cook EJ, Goulder F, Justin TA, Keeling NJ. Neutrophillymphocyte ratio as a prognostic factor in colorectal cancer. J Surg Oncol 2005; 91 (3): 181-184.

14. Zahorec R. Ratio of neutrophil to lymphocyte counts - rapid and simple parameter of systemic inflammation and stress in critically ill. Bratisl Lek Listy 2001; 102 (1): 5-14.

15. Galliazzo S, Nigro O, Bertu L et al. Prognostic role of neutrophils to lymphocytes ratio in patients with acute pulmonary embolism: a systematic review and meta-analysis of the literature. Intern Emerg Med 2018; 13 (4): 603-608.

16. Tamhane UU, Aneja S, Montgomery D, Rogers EK, Eagle KA, Gurm HS. Association between admission neutrophil to lymphocyte ratio and outcomes in patients with acute coronary syndrome. Am J Cardiol 2008; 102 (6): 653-657.

17. Kaya H, Ertas F, Soydinc MS. Association between neutrophil to lymphocyte ratio and severity of coronary artery disease. Clin Appl Thromb Hemost 2014; 20 (2): 221.

18. Guzel M, Ozgen E, Terzi O, Demir MC, Yucel M, Baydin A. Relationship between neutrophil-to-lymphocyte ratio, d-dimer and troponin-I values and pulmonary embolism severity index Ann Med Res 2019; 26 (4): 653-657.

19. Cho KH, Jeong MH, Ahmed K et al. Value of early risk stratification using hemoglobin level and neutrophil-to-lymphocyte ratio in patients with ST-elevation myocardial infarction undergoing primary percutaneous coronary intervention. Am J Cardiol 2011; 107 (6): 849-856.

20. Poisson SN, Johnston SC, Josephson SA. Urinary tract infections complicating stroke: mechanisms, consequences, and possible solutions. Stroke 2010; 41 (4): e180-184.

21. Karagoz I, Yoldas H. Platelet to lymphocyte and neutrophil to lymphocyte ratios as strong predictors of mortality in intensive care population. Rev Assoc Med Bras (1992) 2019; 65 (5): 633-636.

22. Perez-de-Puig I, Miro-Mur F, Ferrer-Ferrer $M$ et al. Neutrophil recruitment to the brain in mouse and human ischemic stroke. Acta Neuropathol 2015; 129 (2): 239-257.

23. Xue J, Huang W, Chen $X$ et al. Neutrophil-to-Lymphocyte Ratio Is a Prognostic Marker in Acute Ischemic Stroke.J Stroke Cerebrovasc Dis 2017; 26 (3): 650-657.
24. Lim HH, Jeong IH, An GD et al. Early prediction of severity in acute ischemic stroke and transient ischemic attack using platelet parameters and neutrophil-to-lymphocyte ratio. J Clin Lab Anal2019; 33 (3): e22714.

25. Altintas O, Altintas MO, Tasal A, Kucukdagli OT, Asil T. The relationship of platelet-to-lymphocyte ratio with clinical outcome and final infarct core in acute ischemic stroke patients who have undergone endovascular therapy. Neurol Res 2016; 38 (9): 759-765.

26. Xu XR, Carrim N, Neves MA et al. Platelets and platelet adhesion molecules: novel mechanisms of thrombosis and anti-thrombotic therapies. Thromb J 2016; 14 (Suppl 1): 29.

27. Chen Y, Xiao Y, Lin Z et al. The Role of Circulating Platelets Microparticles and Platelet Parameters in Acute Ischemic Stroke Patients. J Stroke Cerebrovasc Dis 2015; 24 (10): 2313-2320.

28. Sansanayudh N, Numthavaj P, Muntham D et al. Prognostic effect of mean platelet volume in patients with coronary artery disease. A systematic review and meta-analysis. Thromb Haemost 2015; 114 (6): 1299-1309.

29. Idil Soylu A, Arikan Cortcu S, Uzunkaya F et al. The correlation of the platelet-to-lymphocyte ratio with the severity of stenosis and stroke in patients with carotid arterial disease. Vascular 2017; 25 (3): 299-306.

30. Meyers PM, Schumacher HC, Connolly ES, Jr., Heyer EJ, Gray WA, Higashida RT. Current status of endovascular stroke treatment. Circulation 2011; 123 (22): 2591-2601.

31. Ghobrial GM, Chalouhi N, Rivers L et al. Multimodal endovascular management of acute ischemic stroke in patients over 75 years old is safe and effective. J Neurointerv Surg 2013; 5 Suppl 1: i33-37.

32. Leclercq A, Houard X, Philippe M et al. Involvement of intraplaque hemorrhage in atherothrombosis evolution via neutrophil protease enrichment. J Leukoc Biol 2007; 82 (6): 1420-1429.

33. Massiot N, Lareyre F, Voury-Pons A et al. High Neutrophil to Lymphocyte Ratio and Platelet to Lymphocyte Ratio are Associated with Symptomatic Internal Carotid Artery Stenosis. J Stroke Cerebrovasc Dis 2019; 28 (1): 76-83.

34. Pektezel MY, Yilmaz E, Arsava EM, Topcuoglu MA. Neutrophil-toLymphocyte Ratio and Response to Intravenous Thrombolysis in Patients with Acute Ischemic Stroke. J Stroke Cerebrovasc Dis 2019.

35. Tokgoz S, Kayrak M, Akpinar Z, Seyithanoglu A, Guney F, Yuruten B. Neutrophil lymphocyte ratio as a predictor of stroke. J Stroke Cerebrovasc Dis 2013; 22 (7): 1169-1174.

36. Petrone AB, Eisenman RD, Steele KN, Mosmiller LT, Urhie O, Zdilla MJ. Temporal dynamics of peripheral neutrophil and lymphocytes following acute ischemic stroke. Neurol Sci 2019.

37. Brooks SD, Spears C, Cummings $C$ et al. Admission neutrophil-lymphocyte ratio predicts 90 day outcome after endovascular stroke therapy. J Neurointerv Surg 2014; 6 (8): 578-583.

38. Maier B, Gory B, Taylor G et al. Mortality and Disability According to Baseline Blood Pressure in Acute Ischemic Stroke Patients Treated by Thrombectomy: A Collaborative Pooled Analysis. J Am Heart Assoc 2017; 6 (10).

Received April 27, 2020. Accepted May 12, 2020. 